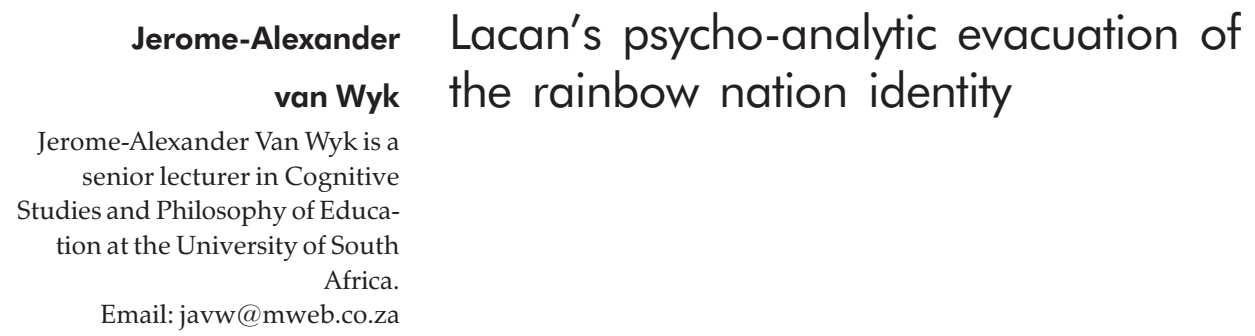

\title{
Lacan's psycho-analytic evacuation of the rainbow nation identity
}

Given the increasing displacement of the essentialist racial categories of the past and the emergence of often-superficial theorisations of race in terms of the diverse South African experiences of difference and Otherness, this article seeks to reassess and reassert our theoretical frameworks that constitute or question the idea of our rainbow nation identity formations. The article employs Lacanian psychoanalysis to contest rainbowism for its under-theorised and often simplistic perspectives on the one hand, and its ideological and limited representations on the other. Key words: rainbow nation, identity, Lacanian psycho-analysis, rainbowism, South African identity.

\section{Introduction}

The apt coinage of the rainbow nation metaphor was meant to provide comfort and hope to South Africans when they experienced a period of distinct political and social stress. Rainbowism subsequently became an almost knee-jerk response which now tends to coalesce around the dilemmas South Africans experience "as a hangover from the excesses of apartheid" (Shepperson \& Tomaselli, 2001: 49). Whether used in an astute or superficial manner, rainbowism has become the new ideology to express, on the one hand, that South Africanness cannot assume a single standard which aspires to be monolithic in character but also, on the other, to pursue a socio-political environment in which the interests and identities of all are said to be of equal concern at the level of government and civil society. Since the only authentic or common factor among us is our sense of identity which is linked to a "sense of place" (Stein, 1987: 87), the boundaries and links of the self within the rainbow seem to be (in)formed by a sense of psychogeography in which the rainbow becomes the new symbol of opportunity for self and the Other: "New symbols are sought to replace the void left by the absence of the old" (Stein, 1987: 87). The rainbow metaphor, we may argue, becomes a strong political phenomenological representation of selfhood 
which is both "relational and collectivist" in its intent (Richards, 1997: 5). Thinking through identities, rainbowism as a quasi-neologism figures strongly in the transforming South African semiotic system, seeking to recognise and celebrate racial/cultural identities. These ultimately tend to succumb to a spirit of relativism, rather than the homogeneity of universalism or the hierarchicism of evolutionists: "The relativists (...) are pluralists: "different but equal" is their slogan, equality and diversity their democratic aspiration" (Shweder, 1991: 114).

However well intentioned, rainbowism (see also Owusu-Bempah \& Howitt, 2000: 33) is contested in this debate primarily for its undertheorised and often simplistic perspectives on the one hand, and its ideological and limited representations on the other. Given the increasing displacement of the essentialist ideological categories of the past and the present race debates with regard to the diverse South African experiences of difference and Otherness, it may become necessary to reassess and reassert theoretical frameworks that constitute or question the idea of identity formation. The prevailing untheorised assumptions of the discourses of rainbow nation representationalism notwithstanding, grouped identities in general and cultural identities in particular vis-à-vis their political articulation, seem to have lapsed unabatedly into what Suleri (1993: 244) refers to as "tyrannical clichés about the political correctness of the thought police". We may, for example, glean the "coming to voice" of the notion of "black" which simply became a generalised identity representation in the 1980's in South Africa and elsewhere. This occurrence seems legitimate since it had derived from a set of determinate historical conditions in which new forms of cultural antagonism and political agency were constructed (Mercer, 1992: 429). Black representation as political category, even in South Africa, was necessary in order to find a critical voice, since the "politics of difference", according to bell hooks (1993: 424), cannot be separated from the politics of racism. A decade later since the 1994 democratic elections in South Africa the question remains how do we proceed. How does the semiotics of rainbowism become less political and more socially relevant, for "given that race discourse was produced in a thoroughly visual culture (own emphasis), it is necessary that the visual itself be used against the scopic regime of race" (Seshadri-Crooks, 2000: 158). The question is how does an anti-essentialising and oft-displaced rainbow notion embrace a radically different subject-position which does not seek to assimilate difference but rather speaks from a position of equality as part of a shared struggle to assist us to decolonise our 
inherited and socialised models of subjectivity. Our personal and group identities which are often subsumed in the idea of rainbowism have become increasingly important in "stabilising" our new democracy and ensure a hope-full economic and social future. This is likely to happen if we reassess our taken-for-granted rainbow nation status in that we understand and work towards changing the ideological processes of misrepresentation (Edward Said in Brantlinger, 1985). For this process we require an appropriate framework of tools to bring the subject of race and racial differences, as encountered in the rainbow metaphor, into representation in a more diverse and anti-essentialist manner.

\section{The struggle for an appropriate theoretical framework}

The focus in this article to theorise the rainbow identity, is premised on the prevailing anti-intellectualism towards attempts of examining identity and the sluggish attempts of cultural interpretative practitioners who tend to approach identity issues in terms of often emotional and monolithic cultural critique of their own/grouped, lived experiences. Beyond homogeneity there is a good case to be made for relativists who embrace pluralism (Shweder, 1991: 1114). South Africa has the most official languages as well as the most colours in its national flag - an unrivalled position in the world. From this symbolic position of posturing on the one hand, to people's actual lived experiences on the other, it comes as no surprise that in seeking to understand the different identities that trade under the often amorphous banner of South African, there are different ideological struggles at work between and among different forms of identifications within the discourses of history, race, culture and so forth. The rainbow metaphor - politically speaking-seems primarily confined to race, to the neglect of gender, class, and religion. The question is how do we arrive at a form (not necessarily selective and single) of identification that is based on equivalence if for many South Africans the binary notions of black/white or African/European remain so fresh and vivid in their institutionalised forms. The African-American experience of the epistemic binary form

of either/or rhetoric as echoed by bell hooks (1993: 426) is insightful to clarify the notion of rainbowism:

When black folks critique essentialism, we are empowered to recognise multiple experiences of black identity that are the lived conditions which make diverse cultural productions possible. When this diversity is ignored, it is easy to see black folks as falling into two categories: nationalist or assimilationist black-identified or white- 
identified. Coming to terms with the impact of post-modernism for black experience, particularly as it changes our sense of identity, means that we must and can rearticulate the basis for collective bonding (...) Many of us are reluctant to face this task as many nonblack post-modern thinkers who focus theoretically on the issue of "difference" are to confront the issue of race and racism.

Ironically, in the area of physical science the rainbow phenomenon is the effect of different colours formed by the refraction and reflection of sunlight by raindrops in the air. Refraction and reflection similarly are representative of all anti-essentialising functions of our social identities so that the articulation of varying permutations of identities generally become encoded in terms of representations of various race, gender and class positions. The politics of identity arguably becomes the politics of positioning - a positioning which has no absolute guarantee in the unproblematic, transcendental law of origin (Hall, 1993: 395). This discursive framework resonates Fanon's (1986: 109) subject position of us all being "without horizon, colourless, stateless, rootless - a race of angels". Derrida (1978: 123) similarly, in an emphatic stance rejects all archaeological grounds or eschatological vision of the subject's identification. For this reason the postcolonial notion of rainbow positioning, through the workings of refraction and reflection emphasizes displacement, hybridity and difference.

The struggle of theorising any identity-formation in the South African context - theoretically at least - may call upon a broader anti-essentialist approach if we were to enhance the democritization project and neutralise conflictual group-specific struggles - a view which Chantal Mouffe (1985: 100) argues is a progressive struggle and which does not necessarily depend on its place of origin but rather forging links in the present with other people's struggles. In terms of the often homogenising group-specific identifications Sara Suleri (1993: 244), a woman theorist of Pakistani descent, theorises her own post-colonial and lived experience when she protests that she is somewhat uncomfortable if not embarrassed with the prospect to "contemplate such a simplistic binarism (...) by situating both its knowledge and its ignorance in relation to the devastating rhetoric "us and them" that beleaguers issues of identity formation today". The refracted and anti-essentialist and therefore expansive thrust envisaged in this article derives from the Derridean assumption "there is no outside the text" (il n'y a pas de hors-texte), i.e. a view entailed in the decentring process of the human subject who 
always and single-handedly determines the centre of identity construction. This decentring process of "border crossings" (Jacobus, 1998: 127) generally informs the differential discourses of an unending oscillation between and displacement of opposites in the binaries of black/ white, male/female, rich/poor, and so forth. This play is mobilised and renewed precisely because of the lack of any final and often spurious grounding authority, the absence of the transcendental signifier which "at one time or another, would place a reassuring end to the reference from sign to sign" (Derrida, 1976: 49). While we are South African by birth, the rainbow nation concept will always gravitate to "differential semiotic regions" (D'Andrade, 1986: 15) where the human consciousness continually undergoes cultural and personal shifts.

\section{The role of psychoanalysis}

We may suspect a conditional capitulation when bell hooks (1993: 427) subsequently argues that postmodern culture of continual shifts (à la Derrida) with its decentred subject can become the space where "ties are severed [from the Other] or it can provide the occasion for new and varied forms of bonding". The latter hints at another theoretical perspective, i.e. how a South African rainbow identity cannot constitute an essence. The constantly refracted/reflected positioning will not let itself be locked into a fixed and therefore limited system of particular differences and, as a result, yield a single hegemonic identity. However, in emphasising the ways in which Black, Coloured, Indian or White South Africans homogenise and therefore generalise each Other, there may be a serious risk of overlooking the ways in which such hegemonic identity discourses typically deploy strategies of exaggerating and playing off difference among diverse Others. The deployment of psychoanalysis in this debate is significant since South Africans seem to invest greatly in appearance (race) and by exploring "the physical import of race (...) one could understand its resilient non-sense" (Seshadri-Crooks, 2000: 2). However complex and heterogeneous our refracted rainbow identities, the co-ordinates of identity discourse analysis can be broadened and possibly removed from its own stasis, circularity and essentialism if we are to see each other differently. This may demand shifting the focus from Others (without denying their existence) to an analysis of the narrative structures and processes which examine the over-determined and contradictory interactions as well as ideological rainbowism codes which produce forms of Othering but which are not reducible to it. 
Lacan's peculiar formulation of psychoanalytic theory provides an appropriate theoretical framework to decipher the pluralism of subject constitution or position beyond mere race (Bracher, 1993; SeshadriCrooks, 2000; Lupton, 1998). The notion of psychoanalysis as a hermeneutics of the psychosomatic is therefore fitting in the meta-theoretical debates of rainbowism as Julia Lupton (1998: 194) declares: "I take psychoanalysis as an account of social symbolisation and its symptomatic fallouts, the products and remainders of the dialectic processes of subject - and nation-for-mation". The representation of "the Other" becomes an anti-representational stance in the Lacanian sense of first subjecting the self to alienation in the network of relations, i.e. subjecting it to the Otherness which in fact constitutes the very struggle for understanding and recontextualising who we are.

Psychoanalysis in this context pursues therefore the notion of identity premised on Lacan's "lack of being", i.e. engaging the Other in order to conceive of the language we use and its role in "representations". The call to theorise refracted/reflected rainbow experiences in terms of deploying Lacanian psycho-analysis challenges and subverts any fixed location of identity. Psychoanalysis moreover assists pluralists in refraining from succumbing to the "totalising gaze" of rainbowism, for everyone could always be different and "identity positioning" is just that, as Amit Rai (1998: 114) reminds us: "Failure should not bother us, but it might cause us to wonder at those who imagine they have succeeded".

\section{Psychoanalysis and the mirror}

Gayatri Spivak (1990: 220) supports the radical possibilities that may surface when identity positioning is problematised, i.e. when " the hegemonic discourses, the holders of hegemonic discourse (...) dehegemonize their position and themselves learn how to occupy the subject position of the other". In this process Lacanian human subjectivity and the understanding of an anti-essentialised rainbow identity position only becomes possible by subjecting oneself to the "Otherness" as represented in the mirror of the Lacanian Symbolic Order. The metaphor of the mirror henceforth becomes the subverting element in all subjectivities in the struggle for identity within the proximity of difference and otherness in our South African rainbow nation context. Shweder (1991: 33) argues that even when differences between things matter "those differences are revelatory of progress or advance". In the functioning of differences the mirroring of an image or a mirage is 
caused in the context of the rainbow "visual culture" (Seshadri-Crooks, 2000). In the area of natural science this visual phenomenon is due to the refraction and reflection of light and it is said that a common mirage (self-deception) usually occurs in the desert (Geddes \& Grosset, 2001). Appropriate however to Lacanian psychoanalysis, the desert is symbolic of emptiness - always lacking, and therefore desiring of the Other. The search for a rainbow subjectivity may go beyond a "verifiability principle" which demands an "operational definition" (Gellner, 1985: $10)$, and which may force us to evacuate all resemblance to start from a shifting discourse which in Foucaultian parlance is " banal, repeated a thousand times, yet almost always silent" (Foucault, 1983: 34).

\section{Lacan's psycho-analytic evacuation of identity construction}

To understand the "scopic regime of race" (Seshadri-Crooks, 2000: 158) the discourse of the mirror metaphor as surfaced in two very familiar South African events which, in terms of identity positionings, and which are still very much alive in our national psyche prove useful in this discussion. Since we live all the time in the reflection and refraction of the Lacanian mirror stage we proceed in terms of the psychoanalytic approach to clarify the feelings of self-loathing as representing an act of evacuation or "emptying out", experienced by the characters in the following accounts as reported from two different sources:

Happy Sindane (Tsedu, 2003: 21):

When Happy Sindane looks in a mirror he sees a white boy looking back at him. And for him that is important. He is white, he insists, and all he needs is for his real white parents to come forward. Failing that, any white parents would then have to do.

Nine years after the white establishment lost political power and a black government took over and instituted programmes designed to empower black people, one would have hoped that blackness would be in and whiteness out - in a manner of speaking.

What with affirmative action, empowerment models, charters for equity and a growing black middle class, blackness is the thing, it puts you in the front of the queue. But
Verwoerd/Tsafendas (Stephen, 2003: 111):

South African born actor Antony Sher dramatises the assassination of Hendrik Verwoerd in his play, ID.

For the play to work as a drama, says Sher, it needed the other side of the story: Verwoerd. The two men (Tsafendas and Verwoerd) were obsessed by the same thing-identity - though in very different ways; Tsafendas in a personal sense. Verwoerd on a national scale.

The result is a play that is in turn moving and uncomfortably comic. It is both a story about identity, and a fine English murder whodunnit.

Tsafendas meets Helen Daniels, a coloured spinster, when he rented a room from her in Cape Town.Daniels is conservative/religious 
Happy says no, he is part of the previously advantaged and shall remain so.

Blood tests have now been done and science says Happy is not white. But he will have none of this science mumbo jumbo. He was kidnapped from his white parents and that is his story. Happy has to live with his denial of himself. He is never going to be white, whatever benefits he hopes to achieve from that as an electrician.

It is recognition of the need to transform society in a way that recognises the good values of our African heritage that will help us free Happy from the slave mentality that decrees for him that white is better. And when we transform his society in that way, there will be enough goodness in blackness and Africanness to make Happy cherish the reality of who he truly is.

Then he will stop trying to become who he is not, who he can never be. He will accept that his life does not depend on whether he is white or black, but on what he makes of it through education and a will to do an honest day's work. and is appalled when it comes to light that Tsafendas is not, as she thought, a coloured man, but classified white. The irony is that Tsafendas is not white. Born in Mozambique he is the son of a Greek man and his coloured servant.

In the play Verwoerd giggles at his own witticisms, devastatingly blind to his own hypocrisy - bafflingly certain of his own superiority: "I have been put on this sweet Earth with a purpose, a gift from on high", he tells his reflection in the bathroom mirror.

Yet, like Tsafendas, Verwoerd is actually an outsider. He was born in The Netherlands and his liefling, Betsie, is rumoured to have coloured blood.

He shares other things with Tsafendas: poor sleeping habits, a propensity to talk to himself ... and a certain kind of madness. After a failed assassination attempt in 1960 Verwoerd discusses the culprit's (David Pratt) fate with a psychologist: "I am trained in psychology, doctor" he says, "I know my madmen. This one shows clear signs of megalomania. He sees himself as a political prophet a saviour. $\mathrm{He}$ thinks he knows what's best for South Africa. What could be madder than that?"

Sher's own sympathy for Tsafendas is clear. The doctor explains, "He is, in the end, a coloured man who has suffered a life-time of almost unimaginable isolation and dislocation, kicked from one country to another."

The similarities of "looking" or "mirroring" (albeit a mirage) between the two renditions above are patently stark. In the rainbow nation we all "look" at others, through the differences between us and articulate these in terms of language to make sense for ourselves. The centrality of language in the assumptions of the unconscious of Happy, Verwoerd and Tsafendas (via the mirror stage), become manifest in the modalities that shaped their social reality. As with Happy, Tsafendas and Verwoerd, the rainbow people also constantly seek to write and rewrite themselves figuratively, defining and redefining their identities through others. Arguably nothing, not even the representations of 
subjectivity, is subjected in a simple and unproblematic way to a dominant subject, whether identified as author, cogito, archetype, or field of knowledge. Hartman, 1981:2) argues that "we have been accustomed to bypass the peculiar entity "self" and say that things are subject to language, or language-determined indetermination. Even the self, that is, has its boundaries fixed or unsettled by language". For our understanding of identity construction in the context of rainbowism representation and misrepresentations we are confronted by Lacan's departure from objectivity through language in relation to subject constitution which remains "almost always silent" (Foucault, 1983: 34).

\section{Lacan's departure from objectivity}

Following Nietzsche and Bataille, Lacan transports us to the pre-Oedipal play of desires so that we can continually "play in the psychic economy" (Bracher, 1993: 12) to create and redefine ourselves, without giving ourselves through language a fixed unity and therefore a selfassured sense of authority and authorship as rainbowism often assumes. As a result Lacan evidences an insightful move to interpret Freud's unconscious as a language and proceeds to interpret language along Saussurian lines as the free play of signs and signifiers, without end or unity, as in our case, are effected through the refractions in the rainbow. This "lack" of objectivity via the language of rainbowism, arguably enhances the creative function of the rainbow metaphor, "weaving together many strands and reconnecting them in innovative ways" (Chaitin, 1996: 3). The mirror as language facilitates these strands and reconnections in the life of Happy Sindane and his different families / Verwoerd and Tsafendas and all the characters they encounter from different walks of life. Yet, they remain just that: a mirage.

The resemblance purported in the mirror image is significant and attempts at rethinking and deepening our discourse of rainbow identity may be lacking if we were not also mindful of the "never-present past" Lacanian discourse of subjectivity and representation (Lacan, 1977a, 1977b). Lacan returns to the notion of language, particularly its intertwining and reconnecting implications with subjectivity, but in which he encourages us to read Freud as if "reading" a dream or mirage, that is, according to Freud's own interpretive methods. This mirage created by the rainbow becomes the "basis" of our desire for the Other, rather than having knowledge (i.e. pretending to know) of the other in the rainbow amalgam. Consistent with Barthes and Derrida, Lacan too rejects the notion of a single unified subject that has direct 
access to its own (and others') life meaning of self-identity and like Derrida, would subject them rather to the working of playful signifiers. Lacanian psychoanalysis is repeatedly made to "turn back upon itself" and constantly re-examine its concepts, rituals, (e.g. the notion of rainbowism) from the vantage-point offered by their own discoveries in their original unsystematised state as clarified by Bowie (1987: 100, 101). For Lacan (1977b: 31-32) argues that, it is important to recognise that the unconscious is not a submerged consciousness, a rational system that is somehow invisible; it is an entirely other form of reason, logic and desire. For Happy Sindane the mirror is the gateway to himself as Tsafendas is for Verwoerd to understand himself. Lacan's "dictum" is that desire through the mirror is the desire for the Other.

It would seem that rainbowistic representations are only "understood" in relation to desire, i.e. the indirect and often conflictual understandings of who we and others are. Lacan pursues therefore a non-representational view which results in what can be regarded as a "re-reading of psycho-analysis itself" (Felman, 1987: 9). Lacan demonstrates how the implications of psychoanalysis, for writing, i.e. refracting and reflecting our identities suggests "different or other" or even ambiguous modalities in which psychoanalysis has transformed the procedures that would be available to the rainbow subject. Felman (1985: 181) suggests that Lacanian analysis, while recognising that "difference inhabits language", also asserts that the unconscious is not just that state which is read, but also in fact "that which reads". In fact the refractions and reflections of the mirror make our rainbowistic discourse readable. In the framework of this non-objectivist stance Lacanian recognition of the "unconscious as a reader" suggests to the rainbow people a different perspective of identity construction which is infinitely differential, i.e. it not being essentialist (see Williams, 1995: 75; Felman, 1982: 21). For Lacan (1977a: 295) therefore the unconscious is primarily structured like a language, and to develop his discourse of the linguisticality of the unconscious, he draws extensively on the work of Levi-Strauss (1967: 203): "The unconscious (...) is always empty - or more accurately, it is as alien to mental images as is the stomach to the foods that pass through it. As the organ of the specific function, the unconscious merely imposes structural laws upon inarticulated elements that originate elsewhere -impulses, emotions, representations and memories."

Happy and Verwoerd only seem to "find" themselves through the linkages that constitute the pathways of desire, as illustrated in terms of 
Hegel's master-slave dialectic - a parable in which the slave can work for the master only by repressing his own desires, founded in emptiness, and as a result transcend himself. Lacan refers to Sartre's dialectic of the self, its lack or loss and "the Other" vis-à-vis the act of seeing and being as clarified by Hollinger, (1994: 91). As a result, the Freudian notion of libido is significant according to Lacan, to assist us to explore the world through what he calls the "scopic drive" (Sarup, 1992: 35). The rainbow discourse is primarily founded on a visual culture so that we can only articulate who we are through the ideologies of race, for this is our "lived" experiences (Hall, 1966: 55). Therefore, this productive and political process implicates all forms of "looking", for as the object can be looked at, it in turn can look at me - a notion we can apply to Happy, Tsafendas and Verwoerd who produce constant permutations of themselves in terms of how the "empty" subject constructs meaning of who he is beyond the "baffling certainty" of who they are (Sher in Stephen, 2003: 11). The mirror function of transference (Übertragung) in psychoanalysis connects/reconnects images for Happy, Tsafendas and Verwoerd in which an identity substitution is performed beyond mere dialogical processes. Through "carrying across" (Übertragung) Happy and Verwoerd engage in the signifying process of who they are (see Chaitin, 1996: 115).

It is significant in Lacanian anti-totalising critique that Happy, Tsafendas, Verwoerd essentially are nothing more than signifiers operating as a function of speech - who experience a lack of being. According to Lacan (1977a: 292) the lack of being process proves essential for the conceptualisation of language and its representations of identity. In terms of this lack or emptiness, Lacan argues that reading, i.e. defining the trace in language always entails the trace of a nothing (Lacan, 1977a: 320). If man was born prematurely since language existed prior to mankind, the implication therefore is not what the subject "is able" to perceive but rather that seeing has already been determined by images. Bannet (in Bracher, 1994: 25) clarifies that "as the conscious subject is little more than a mechanism which repeats the signifiers and significations already in language, so the unconscious is a mechanism which repeats what has been repressed". Through the mirror of the Other, Happy, Tsafendas and Verwoerd are not incapacitated but are able to repeat the signifiers through their unconscious. They experience in the mirror a "dialogical tension (...) while thematising what these ontologies cover over" (Steele, 1997: 125). In thematising meaning in their lives the Lacanian notion of representation of identity or rather 
signification of an incomplete identity means exploring the self-metamorphosis of the endless and playful process that would yield no fixed or stable meaning but only to conceal a deeper gap, i.e. a gap of an unconscious system of repressed meaning, rooted in Desire. For Lacan the problematic of the meaning-seeking subject therefore becomes implicated in language, acting as a signifier where Happy, Tsafendas and Verwoerd disclose themselves "out of their lack of being" opting to repeat the signifiers already existing in language. White Happy only knows himself through black Happy in as much as Verwoerd only knows himself through Tsafendas, weaving a hermeneutic view into the Lacanian interpretive repertory. This hermeneutic focus is broken in terms of Lacan's "excentric/Other" subject or "I know my mad men" (Sher in Stephen 2003: 111).

\section{The Lacanian excentric subject/excentric identity through the mirror}

When Lacan rejects the notion of a unified collection of thoughts and feelings he locks all forms of self-understanding into an essential split

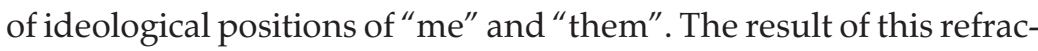
tion is a decentered and empty subject, away from the conception of an explanatory representationalism of identity of race, gender and class. As a result of its inescapable altarity, i.e. the proximity of "difference" and "otherness", the unconscious remains "excentric" to consciousness. In theorising identity the significance of the "excentricity/eccentricity" of the subject patently calls into question the illusory principles governing the resemblance theories of race or culture, especially those bent on monolithic or correct definitions of identity: "But Freud's discovery was to demonstrate that this verifying process authentically attains the subject only by decentring it (a le decentrer) from the consciousness-of- self" (Lacan, 1977a: 79-80). The mirage/illusion of the mirror "causes" Happy and Verwoerd to continue to "illuminate the structure of [their] race" (Seshadri-Crooks, 2000: 71). The nagging feeling of incompleteness, as with the refraction and reflection of light to form the rainbow, must be read in relation to their own desire for recognition - a form of certainty that eludes them.

If Lacan's excentric subjectivity cannot operate in terms of verification processes of resemblance it must be structured and fractured by and upon the notion of self-division, which would imply that the absent subject can never purely be one substantial being, as witnessed in the altarity of white Happy Sindane/black Happy Sindane, and the altarity of Tsafendas/Verwoerd. The separate/divided colours in the rain- 
bow only have recognition and "a certain effects of visibility" (SeshadriCrooks, 2000: 46) within the regime of the rainbow. Lacan argues that since knowledge of who we are or who we think we are as in the case of Happy and Verwoerd, can only be conceptualised in different layers within the human subject that is likely to produce conflict as evidenced in his mirror stage discourse proposed by Lacan. The helpless infant who is not yet objectively in control of its own movements, perceives in the mirror at an imagery level, the mastery of its bodily unity which it objectively still lacks (Benvenuto \& Kennedy, 1986). The mirror stage, for Lacan, is not a mere stage in the history of the individual but rather an alienating stage in which the ongoing struggle of the subject is being waged. The struggle continues because for Happy Sindane the reality is: "He is never going to be White", as is equally true for: "The irony is that Tsafendas is not white". As this is their reality, they cannot escape their reality functioning, as told in their stories: According to Happy, "he was kidnapped from his parents and that is his story" and Verwoerd: "In the play Verwoerd giggles at his own witticisms, devastatingly blind to his own hypocrisy - baffling certain of his own superiority" - prompting J.M. Coetzee to state that "all autobiography is storytelling; all storytelling is autobiography" (Sexton, 2003: 18).

In terms of the reality functioning for Lacan (1977a: 2) the mirror stage is experienced in discourse all the time because the subject projects before him, as his own (illusory?) ideal, the substitute for the lost narcissism of his childhood in which he was his own ideal. Happy, Tsafendas and Verwoerd, as rainbow nation prototypes in Lacanian discourse symbolise neither the eye which sees, nor the reflection seen, but rather the very person who is the process or movement between the two - a contradictory "carrying over" identity in a structure of alienation in the mode of Übertragung. Beyond his challenging theorising of an unproblematic identity formation, Lacan argues that the ego is developed not so much in terms of Freud's "adaptive role" of the ego but rather its misrecognition (meconnaissance), i.e. the refusal to acknowledge thoughts and feelings. This diffuse process already foreshadows the division or the split, i.e. the beginning of the inevitable plurality of subjectivity, where the meaning of the "rainbow" metaphor increasingly emanates from the process of reading the Other, which in psychoanalysis is called transference and "the subject so determined lies in the hands of that interpreter" (Chaitin, 1996: 113). 


\section{The difference and otherness in seeing}

As South Africans our seeing is especially conditioned by our looking. In terms of the displacement of the racial/cultural looking Lacan places significant emphasis on the effects of perception or seeing, i.e. seeing/ looking into the mirror. Seshadri-Crooks (2000: 158) argues that in race discourses we are always confronted with a visual culture of seeing, looking and perception. Happy looks into the mirror and sees someone racially different from himself, as Verwoerd projects himself through the mirror - metaphorically speaking, at Tsafendas. The subject seems to find it easier or more gratifying, according to Lacan, to perceive the unity of an image than it is to produce this unity in its body. The sight of another human being, be it its mother or its own mirror-image, becomes the matrix of a sense of unity, identity and continuity (Lacan, 1977a: 2). In identity theorising the discursive "rainbow" Gestalt is, however, held together in the mirror in an imaginary way and this reflected/refracted image increases its fascination power for the viewer - like when Happy Sindane looks into the mirror and sees a white boy, or when Verwoerd looks into the mirror: "I have been put on this sweet Earth with a purpose". Lacan argues that such fascination with the image in the mirror and desire leads to a state of fictionality and selfdeception which will ultimately result in an alienating effect. The Happy or Verwoerd reflected or refracted in the mirror or in the differential discourse is not the real Happy or Verwoerd. The child within Happy or Verwoerd in its conflictual situation is propelled into identification relations in their alterity only by acknowledging its lack or loss. Only at this moment of alienation in telling its own stories does it become capable of distinguishing itself from the "outside" world and locating itself in the world. When the child recognises the concept of absence, it sees that it is not "one", i.e. complete-in-itself, merged with the world as a whole and the other (Lacan, 1977a: 4-5). Lacan envisages "struggle" moments for deeper identifications in discourse for the rainbow people to illuminate the structure of their identity, whether in terms of race or any other category.

If the state of distance or alienation between White Happy and Black Happy, Verwoerd and Tsafendas becomes problematic then it is because self-identity, Lacan argues, derives from the certainty of the internalisation of a relationship that is based on heterogeneity and difference. The child's recognition of its own image albeit illusory image, means that it has adopted the differential perspective of exteriority on itself (Lacan, 1977a: 4). The Lacanian decentred subject must have 
emerged through a process of differentiation in which it struggles to creatively construct its identity by separating itself from otherness (Lacan, 1977b: 160) and on the basis of this of difference and alienation the individual truly discloses itself as a person or human.

The construction of who the real Happy, Verwoerd and Tsafendas is based on a sense of misrecognition, i.e. the refusal to acknowledge thoughts and feelings, which constitutes for Lacan the cornerstone of the mirror stage where the ego embodies a narcissistic process in terms of which it can bolster a fictitious sense of unified selfhood by finding something in the world it can identify with (see De Beer, 1987: 12). This is actually no unconscious - it is the "structure" in terms of which Happy Sindane or Verwoerd projects outside of himself. It is this outstanding or absence, its seeking (of the Other) in a refractory manner that never ends. In the signification of who I am in the rainbow context every object of desire puts further into place a quest or desire which moves relentlessly in a process of displacement - which Lacan compares to the metonymic play of signifiers, rupturing the totalising claims of a "peaceful" rainbow nation. Desire (unlike a pleasurable pursuit like that of Barthes's jouissance) is rather a movement or energy that is always transpersonal to others, without being hermeneutical in the dialogical sense: "the subject has to find the constituting structure of his desire in the same gap opened up by the effects of the signifiers in those who come to represent the Other for him, in so far as his demand is subjected to them" (Lacan, 1977a: 264).

Desire becomes thus the infinite embodiment of differential identity positions, for desire as productive tension threatens to subvert the unity and certainty or claim to a "pure" racial or cultural identity and thrives only in terms of its own processes and internal logic - the logic of the signifier where "the Other can be either the subject of the object of desire" (Bracher, 1993: 20). Both Happy and Verwoerd look into the mirror where the mirror stage is significant in terms of the subject's narcissism, i.e. between the stage of auto-eroticism and object-love, while itself being taken as a love-object. This imaginary stage embodies the centre of all pre-verbal structures which evolve through a process of la Fading into the Symbolic Order which interpellates the rainbow identity through their differential play (Lacan, 1977a: 118). In the South African account of a multicultural, multi-religious and polyglot society we call upon the Other to respond to: "a play of the signifier, the unconscious has already in its formations - dreams, slips of the tongue or pen or symptoms - proceeded by interpretation. The Other is already 
there in the very opening, however evanescent, of the unconscious (Lacan, 1977a: 118). The differential notion of a rainbow identity therefore becomes a function of inscription in the textured Symbolic Order where an absolute identity is difficult to pin down and "free association must owe its special efficiency to some factor which is consonant with the structure of the unconscious phenomena at issue in analysis slips, dreams and symptoms" (Chaitin, 1996: 196).

\section{Identity in the signifying chain}

The psychoanalytic slips, dreams and symptoms are characteristic in the case of Happy, Verwoerd and Tsafendas, where constant feelings of emptiness, and the constant desire the Other experienced. The rainbow nation subject as epitomised by "emptiness" relentlessly pursues the Other(s) - differently, all the time. This emptiness relentlessly prompts more/other meanings, resulting in a continual displacement of meaning within a signifying chain of gravitating to each other as symbolized in the spirit of ubuntu or togetherness and support. This "togetherness" as may be symbolised in the rainbow semiotic system, signifies "healthy" difference rather than the sameness intended by the principles of resemblance. This difference in the signifying chain proposes a subject which does not represent himself by means of a signifier to another subject; rather a signifier represents a subject for another signifier: "A signifier is that which represents a subject: for whom? not for another subject, but for another signifier (...) The subject is born insofar as the signifier emerges in the field of the Other. But by that very fact, this subject - which was previously nothing if not a subject coming onto being - solidifies into a signifier" (Lacan, 1977b: 198-199).

Within a never-to-be-fully-grasped Happy Sindane the "other Happy" lives comfortably with "this Happy": "Happy has to live with his denial of himself". Similarly, Verwoerd lives comfortably with the Other: "I know my madmen. This one shows clear signs of megalomania. He sees himself as a political prophet, a saviour. He thinks he knows what's best for South Africa. What could be madder than that?" Instead of a coherent, ordered representation of a rainbow self, one finds that within the "unlocatable centre" in the chain, Lacan demonstrates that there will always remain an irreducible otherness between colour, gender or class, which would never be fully placed - since as Barbara Johnson (1987: 226) argues " the letter signifier, can itself not be placed or decided, because the letter as a signifier is not a substance but a function - and it functions as difference." The letter therefore dictates 
the indetermination of colouration or gender in the rainbow and therefore symbolically the non-closure of any theoretical discourse involved in a rainbow representation. No subject, no content of who we truly are can ever be definitive but rather derives from and in a suspension of regrouping into another set of signifiers in our social world of rainbowism.

The pursuit of understanding "who" or "what" Happy, Verwoerd and Tsafendas are, is however no willy-nilly arbitrary discourse because the chain also limits and constantly rearranges the speaker's free$\mathrm{dom}$, for when the signified appears to be within reach of being understood, it dissolves into yet further signifiers. The differentiation process "of presence and absence of chance" (Chaitin, 1996: 125) in identity theorising occurs within the personal/social chain which remains essentially and yet infinitely complex, fluid and dynamic (Lacan, 1977b: 58). Barbara Johnson (1987: 227) clarifies that the signifier is merely an articulation in a chain, not as an identifiable unit. It cannot be known in itself because it is capable of sustaining itself only in a displacement and fully being able to know the other.

The view of displacement of self in the rainbow signifying chain is essentially a discourse of auto-referentiality (Guillaumin, 1995: 50) which is centred on Self, and in terms of Lacanian discourse is always centred on the Other in order "to find" oneself. The auto-referential notion in the South African context of rainbowism proves useful to illuminate the notion of rainbowism as a transcendental signifier or "standard" of a system of difference. This makes every category (of identity of colour, gender, class, religion, etc.) within the rainbow signifying chain refer back to itself.

The articulation of this repeated suspension between displacement and rest becomes the very "basis" of what can be regarded as Lacanian differential reading of identity discourses. In his critical vision of the differential discourse of a deferred process of "rings of a necklace" (Sarup, 1992: 47) is the self-perpetuating imperative that propels the rainbow representation signifying chain - yielding ever-new antihistoricized understandings of who we are in our diverse cultural, racial and religious contexts. The differential dynamics of how we symbolically and materially represent ourselves, according to Lacan, perpetuates the gaze of the other in the chain under the watchful gaze of the law of the father. 


\section{The supremacy of the law of the father in identity signification}

Along with the use of the Name-of-the-Father, the primacy of the phallus and its "enslavement" and conditioning quality is undoubtedly the most poignant theme of Lacanian theory, no matter how un-historicized his arguments may seem. The phallus is not only a signifier but "the signifier of signifiers", for it governs essentially what is meant to designate, as a whole, i.e. the effect of there being a signified, inasmuch as the signifier conditions any such effect by its presence as signifier (Lacan, 1977a: 690, 692, 693). Happy's slave mentality (in the sense of we are all slaves to "the Other") and Verwoerd's links to enslavement to the outsider: "Verwoerd is actually an outsider He was born in the Netherlands - and his liefling, Betsie, is rumoured to have coloured blood."

In the construction of identity the "colonising powers" of the signifier (i.e. the unconscious) over the signified must be grasped in terms of Lacan's notion of the Symbolic Order. The subject's "place" within the cultural context is accorded by the "Law of the Father" -i.e. the Father signifying the symbolic law of culture. Happy is said to be operating under the variations in the dialectical pressure of ethnic heterogeneity that mark social/ racial boundaries (Seshadri-Crooks, 2000: 92): "[Happy] will stop trying to become who he is not - who he can never be!" In thematising who we are the emergence of the Father (in psychoanalytic terms) essentially separates the child from the mother's body and drives its Desire underground into the unconscious. Lacan claims that the Symbolic Order is the Law and the Law is always "the Law-of-the-Father". The antecedent social, racial and linguistic structure within which the signifying subject is "caught", includes all these codes by which a culture "regulates" the system of rainbowistic representation (e.g. psychological, sociological, political, religious, economic) necessary for its own survival. As a result, the cut which had been left by the Name-of-the-Father secures our cultural standing by continuing wrestling the subject from the bosom of "mother" nature. Even in our complex multicultural context in South Africa this cut in identity theorising thus becomes the "springwell" of delayed understanding and making meaning of themselves by constantly seeing/looking into the mirror. This defeats the often essentialist claims: "This is my culture!"

This heterogeneity of culture as refracted in the rainbow clearly cannot be an essentialist idea but graciously operates in terms of the dialectical network of a narrative of "slips, dreams and symptoms" (Chaitin, 1996: 196). Without denying our differential roots, i.e. the pe- 
culiar culture of each one in the rainbow nation context, the Lacanian plural process of signification, in the signifying chain, is regarded as the point of convergence (point de capiton) which Sarup (1992: 53) illuminates: "Just as an upholstery stud or button is the centre for the converging lines or creases on the surface of a taut fabric, so the linguistic point de capiton provides a vantage point from which everything that happens in a given discourse can be situated, both retro-actively and perspectively".

From their various racial and cultural vantage points Happy, Verwoerd and Tsafendas perspectively engage the illusory mirror stage to structure their unconscious (Lacan, 1977a: 840). Happy, Verwoerd and Tsafendas can only understand other cultures and races, i.e. they can only grasp the plurality of signifiers under the eye of the law of the father by knowing their own culture/race, by constantly referring to other signifiers. In their slave mentality and desiring the Other Happy, Verwoerd and Tsafendas paradoxically do not speak the language of their culture/race but is spoken by language (their unconscious) - a view in which the disjunctive position of the Lacanian subject is in "the hands of that interpreter" (Chaitin, 1996: 113), always dispossessed and alienated.

Never identical with itself, the "faulty", "empty", subject is haunted by an unknowable other: Happy is white, he insists, and "all he needs is for his real parents to come forward. Failing that, any white parents would then have to do". Verwoerd equally is "obsessed by the same thing - [white] identity - on a national scale". In Desiring Whiteness Seshadri-Crooks (2000: 3) argues, "I argue that the inaugural signifier of race, which I term whiteness, implicates us all equally in a logic of difference. By Whiteness I do not mean a physical or ideological property (...) By Whiteness, I refer to a master signifier (without a signified) that establishes a structure of relations, a signifying chain that through a process of inclusions and exclusions constitutes a pattern for organising human difference". This process of inclusion and exclusion makes the challenge of an anti-essentialist identity exciting in that there is an "outside" that is "inside", an Other in the play of polarities and resolution which hollows out the "place" of desire in Happy as well as in Verwoerd. In pursuing any representation of oneself in the rainbow coalition this symbolic register is never directly accessible or immediately penetrated by Happy, Verwoerd and Tsafendas but becomes constantly mediated through desire in the hollow presence of language. Since something is always missing, the structure (unconscious) of the 
drive remains open-ended to "allow" rainbow subjects with symbolic positions such as "black", "white", "coloured", indian", etc. The drive oscillates or alter-nates in an "outward-and-back movement" (Lacan, 1977b: 178, 162) and this refraction/reflection becomes a rainbow discourse in a potentially infinite signifying chain.

Instead of pinning down a solid or consolidated personal/culture identity of the rainbow nation, its subjects, in Lacanian tradition, seem inevitably made and remade, from their cultural, racial, social, religious and gender vantage point (point de capiton) in a constant encounter with the Other - a repositioning (unlike the pre-ordained notion of race) which will involve "struggle" between content and dis-content, between temporary fulfilment and emptiness despite the commonplace rote phrases such as "race does not exist" or "race is a construct". The desire to approximate the rainbow nation representations, metamorphisizes and increasingly alludes to the discourse of the superordinate law of the father in terms of which we are gazed upon as we desire the Other. This is structured by the visibility of the rainbow - as activist Sam Walker (2003: 34) in another context, claims, "British history is a tapestry of many colours, and I want to put the black thread back into it". Our symbolic ordering in the rainbow metaphor of racial difference ushers us into theorising "the (...) process of fixing the other [which] is not only seeing; it also involves naming" (Brennan, 1993: 60). The naming process is initiated by the evacuation of all preconceived factuality of difference among "black", "white", "coloured", and "indian" in order to appreciate the other.

\section{The evacuation of meaning in identity construction}

Rainbowism ventures into the ceaseless positions of no-self which are effected through the evacuation of naming and making meaning of ourselves and others. This signals for Lacan a decisive and constitutive lack of being. The absence of a fixed grounding of language or any originary locus implies that the sliding of the signifier over the signified becomes momentarily arrested in specific contexts of the rainbow reflections when we think we know each other. The "indefinite sliding of meanings" (Lacan, 1977a: 126) implies that if each term we use for naming the Other is founded on difference and therefore already requires another name to be understood, all names can only be understood relative to language as a whole. Seshadri-Crooks (2000:5) argues that "visibility in the realm of race should be understood as functioning in support of and as a defence against the fantasy of a totalised 
subject". The lack of the originary locus of language, thus supports the primacy of the rainbow nation as collective as well as myself as individual to remain uncertain. However, the white Happy will only know the black Happy; Tsafendas will only know Verwoerd as Verwoerd will know Tsafendas, when the unconscious becomes the creative locus of the Other beyond ideological naming. This they come to grasp in the regime of visual difference to keep their ever-metamorphisizing identity going without becoming crystallised in an ideological rainbowism. Language can never have an originary totalising locus in describing who we or others are and this is underscored by Lacan's almost contradictory assertion that "one gets nowhere with language".

If Lacan's repudiation of language in its illusory representational sense supports the multiplicity refractions/reflections of the rainbow and therefore spawns differential readings of identities, this poses a challenge to myopic referentiality of categories which illusorily theorise certitude in terms of fixed origins of being White, Black, Coloured or Indian. The reality of a de-ideologised rainbowism is about the shifting of boundaries in which thoroughly heterogeneous plural and different identities are constituted/reconstituted: "The real is not only unknown but is unknowable, not only unsaid but "unpronounceable" (Lacan, 1977a: 316). Lacan would like us to think that he had effectively "dissolved" the self-assured and centred notion of a subject. If Critchley \& Dews (1996: 149) argue that Lacan's notion of subjectivity proposes neither a mechanical nor a sterile view, then it is plausible that " the Lacanian subject contains unique subject-driven mechanisms that both produce and feed upon social discourse in quite unique and particular ways", without "doubling a system of realities". The "I" in the rainbow nation requires no literal Doppelgänger, i.e. a replica of each other but rather requires the presence of the Other within discourse, i.e. within the symbolic writing of one's own identity. White Happy Sindane and Black Happy Sindane, like all rainbowers, feed upon the rainbow visualisation among all groups in the rainbow regime - crediting each other generously with an alternative vision of their possibilities in a plural society.

\section{Conclusion}

The political and social changes in South African society continue to pose great challenges to rainbowism in terms of how we see each other and how these often monolithic perceptions translate in the areas of access to jobs, education and training and the resultant patterns of 
social mobility. Whether real or imaginary, in reality such perceptions are problematic for identity affiliations within the rainbow nation. They tend to structure our private, civic and state enterprises and like Happy Sindane, Verwoerd and Tsafendas who share a sense of psychogeography, we all grapple in the mirror with the mirages and realities of a constantly globalising society, to grasp our positions in the rainbow vis-à-vis the Other(s) whom we constantly interact with.

The "Otherness" of the Lacanian psychoanalysis to illuminate our understanding of the scopic regime of racial identity construction is helpful to understand the "conversion" of the rainbow subject into an "object" being gazed upon and read. Without depersonalising the subject, Lacan would argue for a rainbow nation subject that constantly returns to the Other in order to be constituted. Unlike the essentialist status of our South African racialised/racist past, Lacanian psychoanalysis does not pursue the binary-cum-circularity mode of hermeneutic representation but rather a form of rainbowism where subjects fulfil a "structure", albeit human-social structure, of being constantly subject and object. This displacement of old prejudices based on race, gender and class, and the reversibility of co-responsibility seeks to ensure that no one assumes an arrogant, constitutive, position of a masterful manipulator of others who may or may not be different from us.

Different to the Derridean post-modernist displacement of the subject in terms of the "ideology of the sign", Lacan theorises in a way in which he co-opts in a future anterior sense the unconscious of the subject that is still to be constantly "born", for psychoanalysis in this regard is essentially about "subject-and-nation-for-mation" (Lupton, 1998: 194). Rainbowism does not presume an object "out there" but mirrors the pursuits after the Other to reflect/refract the discourses of our different cultural, religious, gender and racial texts. Instead of imputing and pursuing a pre-ordained and often hegemonic identity of race, gender and culture which tends to be exclusionary and divisive, Lacan's psychoanalysis ushers us into the desert of emptiness to grasp the desperate evacuation (dis-content) of all identities, including the often spurious meanings of myself as self-assured rainbow subject. Rainbow subjectivity as such does not become an end in itself but rather the jouissance of constantly engaging the shifting discourses of how and where we fit in this developing country. Lacanian psychoanalysis defies any illusory/mirage-like anchoring point to allow the sliding of the signifier over the signified which is momentarily arrested in specific contexts of our subject constitution. Sher (2003: 111) illuminates 
Tsafendas' plight: "He is in the end a coloured man who has suffered a life-time of almost unimaginable isolation and dislocation, kicked from one country to another" (own emphasis). In the "psychic economy" (Bracher, 1993: 12) of the rainbow nation our identity positions migrate in innovative ways from one country to another - mirroring/mimicking as for Happy Sindane, Verwoerd and Tsafendas the promise of a fixed abode. In the promise the refracted abode makes our rainbow co-existence possible. Rainbow ideals in the domain of South African economics, governance and social enterprise are developing within the realm of possibilities we are likely to support one another. It is in these contexts between motion and rest, between recognition and misrecognition that we the rainbow nation will find one another, and find ourselves.

\section{References}

Benvenuto, B. \& Kennedy, R. 1986. The Works of Jacques Lacan: An Introduction. London: Free Association Books.

Bowie, M. 1987. Freud, Proust and Lacan: Theory as Fiction. Cambridge: Cambridge University Press. 1991. Lacan. New York: Fontana Press.

Bracher, M. (ed.) 1994. Lacanian Theory of Discourse: Subject, Structure and Society. New York: New York University Press.

- 1993. Lacan, Discourse, and Social Change: A Psychoanalytic Cultural Criticism. Ithaca: Cornell University Press.

Brantlinger, P. 1985. Heart of darkness, anti-imperialism, racism, or impressionism? Criticism 27, 363-385.

Brennan, T. 1993. History after Lacan. London: Routledge.

Chaitin, G. 1996. Rhetoric and Culture in Lacan. Cambridge: Cambridge University Press.

Critchley, S. \& Dews, P. (eds.) 1996. Deconstructive Subjectivities. New York: SUNY Press.

D'Andrade, R. 1986. Three scientific world views and the covering law model. In D. Fiske \& R. Shweder (eds.) Metatheory in Social Science: Pluralisms and Subjectivities. Chicago: University of Chicago Press.

De Beer, C. 1987. Lacan as reader. Journal of Literary Studies 3 (3): 8-22.

Derrida, J. 1976. Of Grammatology. Trans. G. Spivak. Baltimore: Johns Hopkins University Press.

- 1978. Writing and Difference. Trans. A. Bass. London: Routledge.

Dictionary of Science. 2001. Scotland: David Dale House.

Fanon, F. 1986. Black Skin, White Masks. Trans. C. Markmann. London: Pluto Press.

Felman, S. 1982. Psychoanalysis and education: teaching terminable and interminable. Yale French Studies, 21-44.

1985. Writing and Madness: Literature, Philosophy, Psychoanalysis. Trans. M. Evans. Ithaca: Cornell University Press.

- 1987. Jacques Lacan and the Adventure of Insight: Psychoanalysis in Contemporary Culture. Cambridge: Harvard University Press.

Foucault, M. 1983. This is not a Pipe. Trans. J. Harkness. Berkeley: University of California Press.

Gellner, E. 1985. Relativism and the Social Sciences. Cambridge: Cambridge University Press.

Guillaumin, C. 1995. Racism, Sexism, Power and Ideology. London: Routledge.

Hall, S. 1996. Race, articulation and the societies structured in dominance. In H. Baker et al (eds.) Black British Cultural Studies: A Reader. Chicago: University of Chicago Press, 16-60.

- 1993. Cultural identity and diaspora. In P. Williams \& L. Chrisman (eds.) Colonial Discourse and Post-Colonial Theory: A Reader. London: Longman, 392-403. 
Hartman, G. 1981. Saving the Text: Literature, Derrida, Philosophy. Baltimore: Johns Hopkins University Press.

Hollinger, R. 1994. Postmodernism and The Social Sciences: A Thematic Approach. London: Sage Publications. hooks, bell. 1993. Postmodern blackness. In P. Williams \& L. Chrisman (eds.) Colonial Discourse and PostColonial Theory: A Reader. London: Longman, 421-427.

Jacobus, M. 1998. Psychoanalysis and the Scene of Reading. Oxford: Oxford University Press.

Johnson, B. 1987. The frame of reference. In R. Young (ed.) Untying the Text, London: Routledge \& Kegan Paul, 125-243.

Lacan, J. 1970. Of structure as an in mixing of otherness prerequisite to any subject. In R. Mackesay \& E. Danato. (eds.) The Languages of Criticism and Sciences of Man. The Structuralist Controversy. New York: Doubleday Anchor.

—. 1972. Seminar on "The Purloined Letter". Yale French Studies, 48.

—. 1977a. Ecrits. A Section. London: Tavistock.

— 1977b. The Four Fundamental Concepts of Psychoanalysis, London: The Hogarth Press.

—. 1977c. Desire and the interpretation of desire in Hamlet. Yale French Studies, 55-56.

Lane, C. (ed.) 1998. The Psychoanalysis of Race. New York: Columbia University Press.

Levi-Strauss, C. 1967. Structural anthropology. Trans. C. Jacobson \& B. Schoepf. New York: Doubleday.

Lupton, J. 1998. Ethnos and circumcision in the Pauline tradition. In C. Lane (ed.) The Psychoanalysis of Race. New York: Columbia University Press, 193-210.

Mercer, K. 1992. "1968": Periodizing postmodern politics and identity. In L. Grossberg, C. Nelson \& P. Treichler (eds.) Cultural studies. New York: Routledge, 424-449.

Mouffe, C. 1985. Hegemony and Socialist Strategy. London: Routledge.

O'Neill, J. 1989. The Communicative Body: Studies in Communicative Philosophy, Politics and Sociology. Evanston: Northwestern University Press.

Owusu-Bempah, K. \& Howitt, D. 2000. Psychology beyond Western Perspectives. Leicester: The British Psychological Society.

Rai, A. 1998. "Thus spake the subaltern": postcolonial criticism and the scene of desire. In C. Lane (ed.) The Psychoanalysis of Race. New York: Columbia University Press, 91-119.

Richards, G. 1997. "Race", Racism and Psychology: Towards a Reflexive History. London: Routledge.

Sarup, M. 1992. Jacques Lacan. New York: Harvester Wheatsheaf.

Seshadri-Crooks, K. 2000. Desiring Whiteness: A Lacanian Analysis of Race. London: Routledge.

- 1998. The comedy of domination: psychoanalysis and the conceit of whiteness. In C. Lane (ed.) The Psychoanalysis of Race. New York: Columbia University Press.

Sexton, D. 2003. No views to inter. Sunday Times Lifestyle. December 7: 18.

Shepperson, A. \& Tomaselli, K. 2001. Culture, media and the intellectual climate: apartheid and beyond. In R. Kriger \& A. Zegeye (eds.) Culture in the New South Africa 2. Cape Town: Kwela Books.

Shweder, R. 1991. Thinking through Cultures: Expeditions in Cultural Psychology. Cambridge: Harvard University Press.

Spivak, G. 1990. Poststructuralism, marginality, postcoloniality and value. In P. Collier \& H. GeyerRyan (eds.) Literary Theory Today. Cambridge: Polity Press, 219-244.

Steele, M. 1997. Theorizing Textual Subjects: Agency and Oppression. Cambridge: Cambridge University Press.

Stein, H. 1987. Developmental Time, Cultural Space: Studies in Psychogeography. Norman: University of Oklahoma Press.

Stephen, J. 2003. Return of the worm. Mail \& Guardian, September 12. III.

Suleri, S. 1993. Women skin deep: feminism and the postcolonial condition. In P. Williams \& L. Chrisman (eds.) Colonial Discourse and Post-Colonial Theory: A Reader. London: Longman, 244-256.

Tsedu, M. 2003. We're still wearing the self-loathing given to us by colonisers. Sunday Times, July 27: 21 .

Walker, S. 2003. Its time to kick some British butt. Sunday Times, December 7: 34.

Weber, M. 1991. The objectivity of the social sciences. Trans. E. Shils \& A. Finch. On the methodology of the social sciences. Glencoe: Free Press.

Williams, L. 1995. Critical Desire: Psychoanalysis and the Literary Subject. London: Edward Arnold. 